\title{
SISTEM INFORMASI PENJUALAN DAN PERSEDIAAN PRODUK PERALATAN PERTANIAN BERBASIS WEB
}

\author{
Duma Yanti Siringoringo ${ }^{1)}$, Volvo Sihombing ${ }^{2)}$, Masrizal ${ }^{3)}$ \\ ${ }^{1,2,3}$ Fakultas Sains dan Teknologi, Universitas Labuhanbatu \\ email: 11umaringoringo@gmail.com, ${ }^{2}$ volvolumbantoruan@gmail.com, ${ }^{3}$ masrizal120405@gmail.com
}

\begin{abstract}
The rapid development of technology has brought humans into a life side by side with information and technology itself. Nowadays, more and more companies need fast and accurate information services. Processing of sales and inventory data at the Growmart (Farmer Business Branch) Bagan Batu company which still uses the manual method makes recording sales data and printing reports slow and less efficient. To solve this problem, a web-based sales and inventory information system for agricultural equipment products was designed. This web-based information system was built using the PHP programming language and the Cascading Style Sheet (CSS) as content representation, and database processing using MySQL. The result of this research is an information system that helps the sales admin section of the Growmart company to input sales data and equipment product inventory easily, quickly and efficiently..
\end{abstract}

Keywords: Farmer, sales, inventory, quickly, efficiently

\section{PENDAHULUAN [Times New Roman 11 bold]}

Dalam perkembangan dunia yang memasuki era globalisasi, teknologi informasi memiliki peran penting, terutama di bidang ekonomi dan bisnis [1]-[8]. Teknologi informasi berdampak pada berbagai hal seperti meningkatkan efektivitas dan efesiensi pada pengolahan administrasi dan data yang cepat, tepat dan akurat yang bertujuan untuk peningkatan kinerja dari sebuah organisasi [9][16].

Perkembangan teknologi informasi yang amat pesat ini membawa dampak yang besar bagi kehidupan masyarakat. Pengaruh positif merupakan salah satu dampak yang diperoleh. Hal tersebut sangat menguntungkan dan mempermudah segala urusan serta permasalahan yang terjadi di tengah masyarakat dalam hal pengolahan sebuah data. Selain data tersebut mudah dikelola kemudia data tersebut menjadi sebuah informasi yang mudah ditemukan dan didapatkan dengan cepat dan akurat., pada intinya manfaat yang dapat dari perkembangan teknologi informasi dapat memudahkan kegiatan yang dilakukan oleh masyarakat [17]-[20].

Growmart (Cab. Usaha Tani) Bagan Batu merupakan sebuah industry yang bergerak di sektor penjualan peralatan pertanian. Memiliki beberapa pegawai tetap, dan sulit dalam penanganan stok barang yang dikarenakan pihak Growmart dalam melakukan transaksi penjualan dan transaksi pembelian yang masih dicatat secara manual. Proses transaksi yang dilakukan masih relatif cukup lambat dikarenakan masih mengandalkan perhitungan pencatatan dalam buku dan alat konvensional seperti kalkulator. Stok data barang juga masih dicatat dan disimpan pada beberapa buku stok, sehingga sangat lambat dalam melakukan rekapitulasi persedian barang. Pembuatan laporan penjualan juga tidak efektif, karena harus mencari bukti transaksi secara manual. Kendala dalam mengingat harga barang juga sering terjadi, sehingga terjadi kesalahan dalam menentukan harga produk untuk dijual kembali.

Untuk mengatasi permasalahan tersebut, dirancang sebuah sistem terkomputerisasi untuk mempercepat pengelolaan data pembelian, data penjualan, stok persedian barang dan laporan. Saat ini keberadaan Sistem Informasi Berbasis komputer sangat dibutuhkan sebagai alat untuk meningkatkan efektivitas dan efisiensi pengolahan data. Sistem informasi yang dirancang pada perusahaan ini mulai dari penginputan, pencarian, penjualan barang, pembelian, stok dan pembuatan laporan. Dengan menggunakan system informasi ini maka 
pekerjaan pegawai Growmart cabang Usaha Tani dapat dilakukan dengan lebih mudah, praktis, efektif dan laporan yang dihasilkan lebih akurat.

\section{METODE PENELITIAN}

Beberapa tahapan dilakukan pada perancangan sistem informasi penjualan dan persediaan produk peralatan pertanian yang berbasis web, berikut merupakan tahapan yang dilakukan:

\subsection{Diagram Konteks}

Diagram konteks dibuat bertujuan untuk mengetahui keadaan sistem yang akan di bangun. Rancangan diagram konteks pada gambar 1 ini menunjukkan sistem informasi penjualan dan persediaan produk peralatan pertanian pada website.

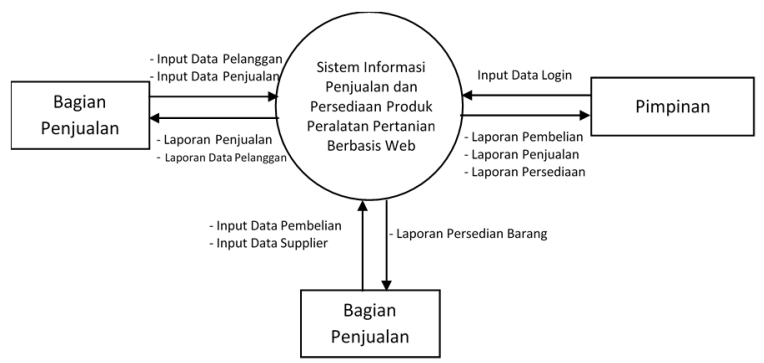

Gambar 1. Diagram Konteks

\section{2. $\quad R A T$ (Relasi Antar Tabel)}

Pada gambar 2 menunjukkan relasi tabel pada Sistem Informasi Penjualan dan persediaan produk pertanian.

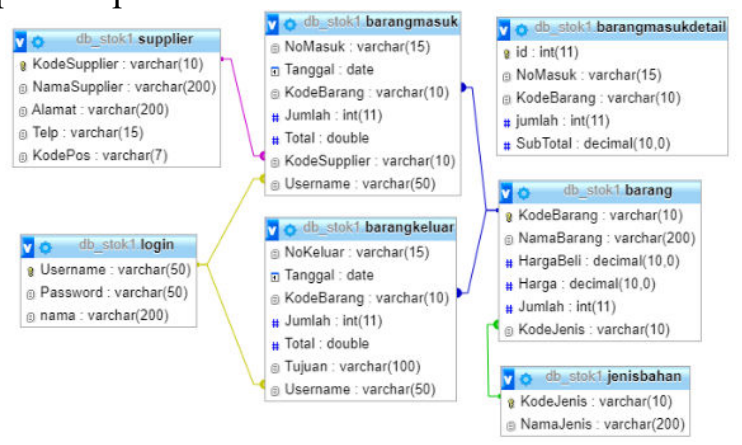

Gambar 2. Relasi Antar Tabel

Relasi yang terbentuk antar tabel terdiri dari 6 (enam) tabel yakni tabel barang, jenis bahan, supplier, barang masuk, barang keluar, dan login.

\subsection{Perancangan Interface}

Perancangan antarmuka yang dibutuhkan oleh sistem yang dirancang terdiri dari : a. Form Login

pada gambar 3 dapat dilihat Rancangan Form Login yang merupakan tampilan awal dari sistem pada saat bagian penjualan pertama kali membuka sistem tersebut.

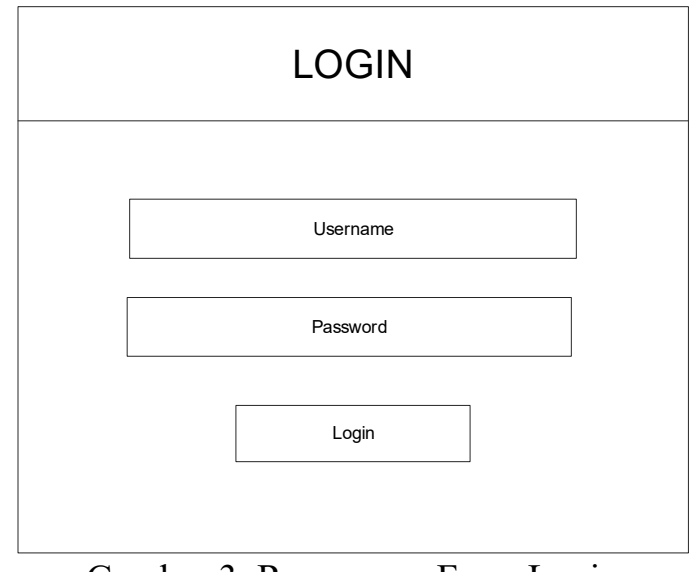

Gambar 3. Rancangan Form Login

b. Rancangan Halaman Utama

Pada gambar 4 dapat dilihat interface admin. Halaman ini hanya dapat di akses oleh admin dengan cara login untuk menginput dan merubah data pada system.

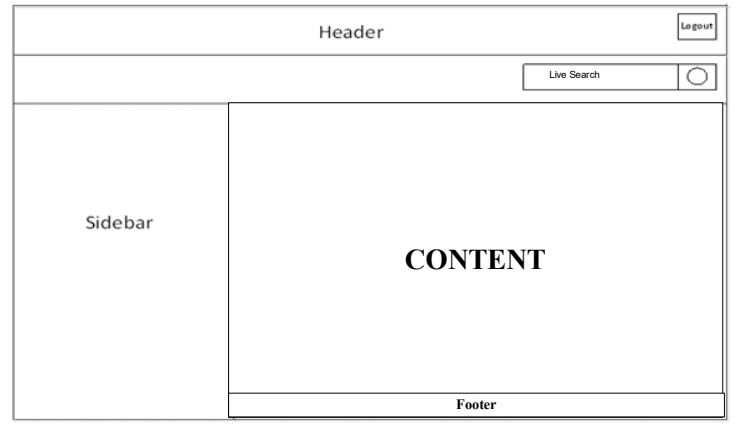

Gambar 4. Rancangan Halaman Utama

c. Rancangan Form Data Jenis

Pada gambar 5 terdapat rancangan form data jenis yang merupakan rancangan form yang berfungsi untuk melihat jenis barang masuk maupun barang yang akan dijual pada Sistem Informasi penjualan dan persediaan produk peralatan pertanian. 


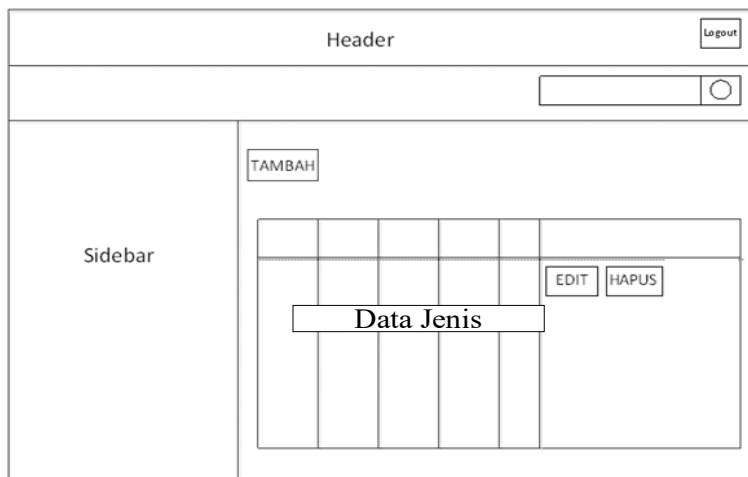

Gambar 5. Rancangan Form Data Jenis

d. Rancangan Form Barang

Gambar 6 merupakan form barang yang digunakan untuk melihat data barang berdasarkan data barang yang telah di input.

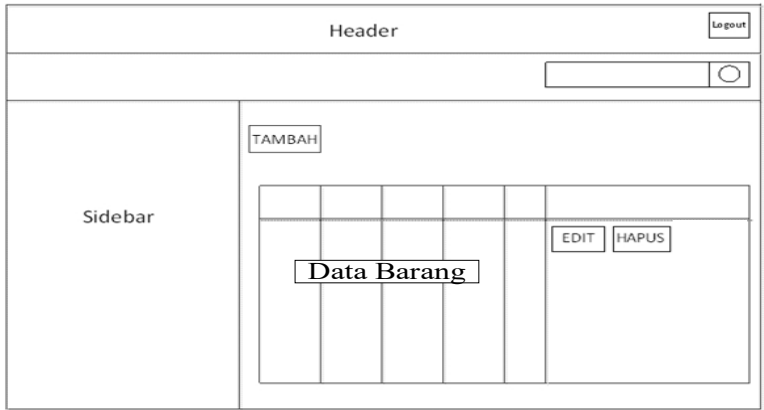

Gambar 6. Rancangan Form Barang

e. Rancangan Form Penjualan_Barang Gambar 7 merupakan form yang pakai untuk mengakses data penjualan barang. Melalui form ini dapat diaktifkan form tambah penjualan untuk menginput data penjualan

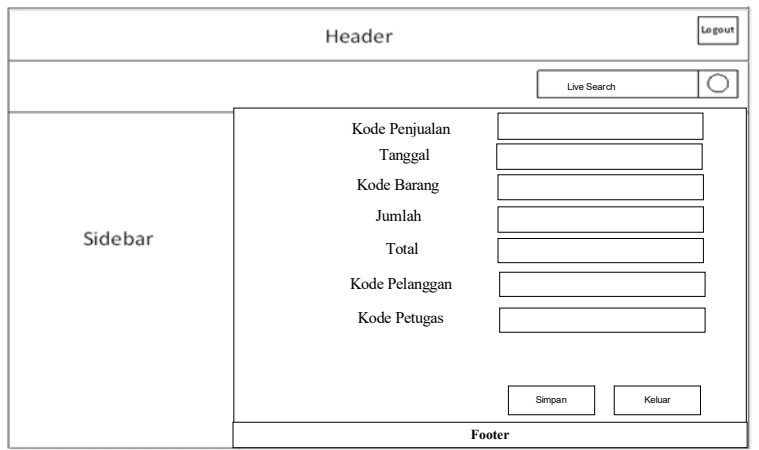

Gambar 7. Rancangan Form Barang

f. Rancangan Laporan

Rancangan laporan dapat dilihat pada gambar 8 .

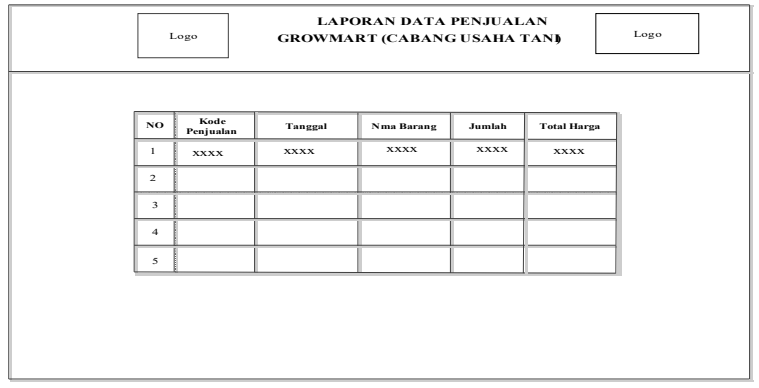

Gambar 8. Rancangan Laporan

\section{HASIL DAN PEMBAHASAN}

Berdasarkan penelitian yang dilakukan maka diperoleh hasil dari perancangan Sistem informasi, yaitu menu form (input sistem) dan report (output sistem). Kedua menu diatas berisi data yang meliputi sebagai berikut:

\section{a. Halaman Login}

Menu Login, berfungsi sebagai untuk mengaktifkan semua menu yang ada. Halaman Login pada gambar 9berfungsi sebagai pengaman sistem agar dapat mengaktifkan main menu dan sub menu yang terdapat pada halaman utama.

\section{Admin Login}

Sign in to start your session

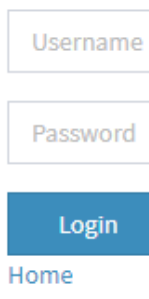

Gambar 9. Halaman Login

b. Menu Utama (Home)

Tampilan menu utama pada gambar 10 berfungsi untuk membuka dashboard layout halaman yang digunakan oleh pengguna sistem. 


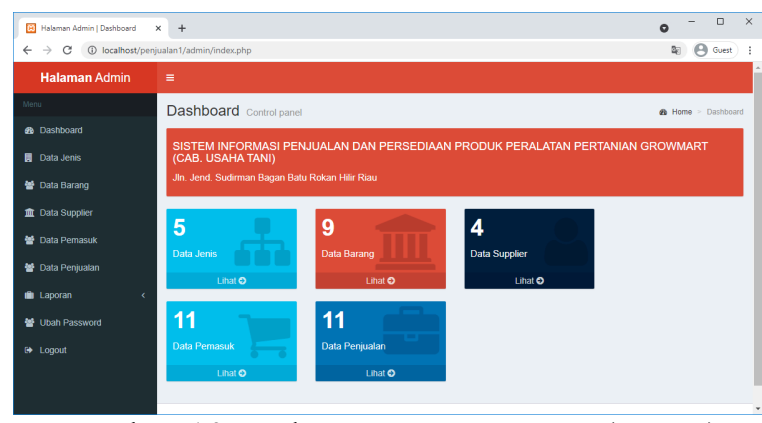

Gambar 10. Halaman Menu Utama (Home)

Halaman Menu Utama (Home) merupakan halaman untuk mengolah pemasukan/pembelian dan penjualan yang dilakukan dengan memilih menu-menu yang ada sesuai dengan kebutuhan.

\section{c. Form Data Jenis}

Pada form data jenis terdapat kolom nomor, kode jenis, nama jenis, dan action yang terdapat button hapus dan ubah, seperti pada gambar 11.

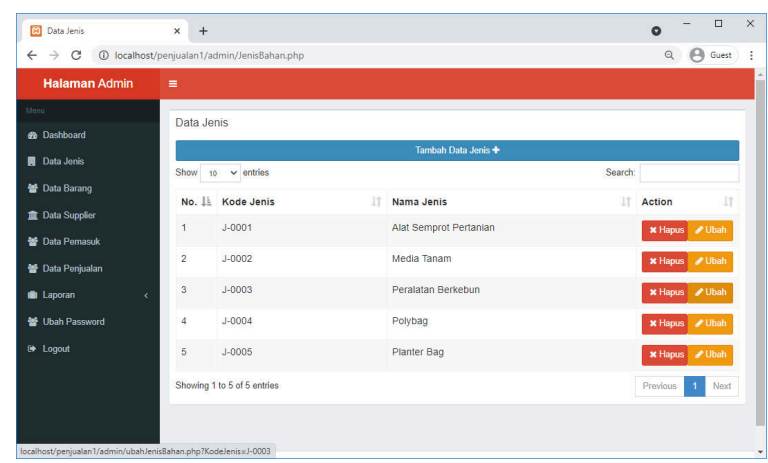

Gambar 11. Form Data Jenis

\section{d. Form Data Barang}

Pada form barang terdapat kolom nomor, kode barang, nama barang, harga barang per unit, jumlah barang yang tersedia, jenis berdasarkan nama barang dan terdapat action button hapus dan ubah. Pada form barang pengguna/admin dapat menambah barang yang ada dengan cara memilih menu tambah barang +. Pada gambar 12 dapat dilihat tampilan form data barang.

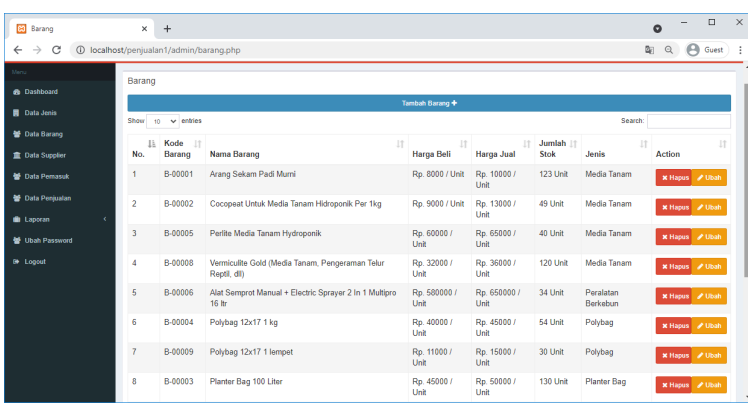

Gambar 12. Form Data Barang

e. Form Penjualan

Tampilan penjualan ini berfungsi sebagai halaman untuk mengubah data siswa, seperti pada gambar 13 .

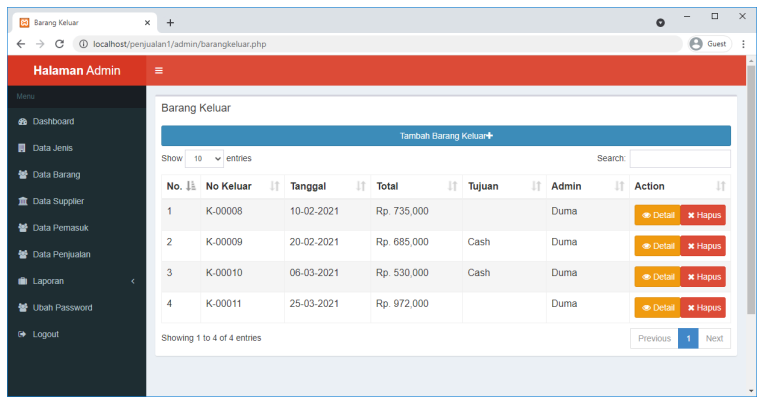

Gambar 13. Form Penjualan

\section{f. Laporan Barang Keluar}

Pada halaman ini seperti gambar 14 dapat dicetak laporan barang yang keluar/dijual dengan memilih menu cetak laporan barang apa saja yang telah keluar..

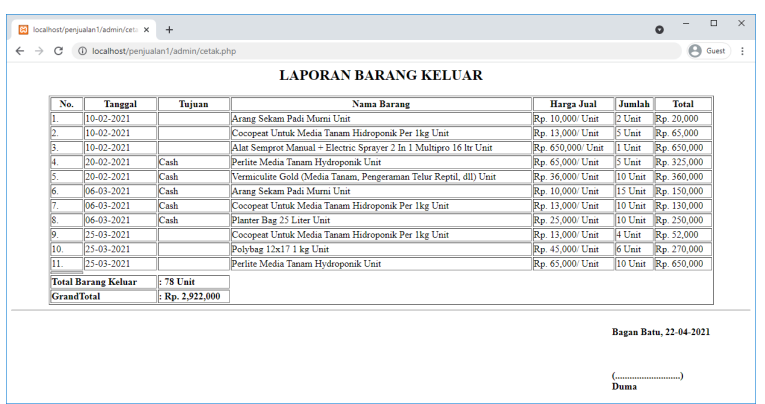

Gambar 14. Laporan Barang Keluar

\section{g. Laporan Persediaan Barang}

Laporan ini dapat dicetak dengan memilih menu cetak laporan stok barang kemudian laporan akan disimpan dalam bentuk pdf dan selanjutnya dapat dicetak.. 


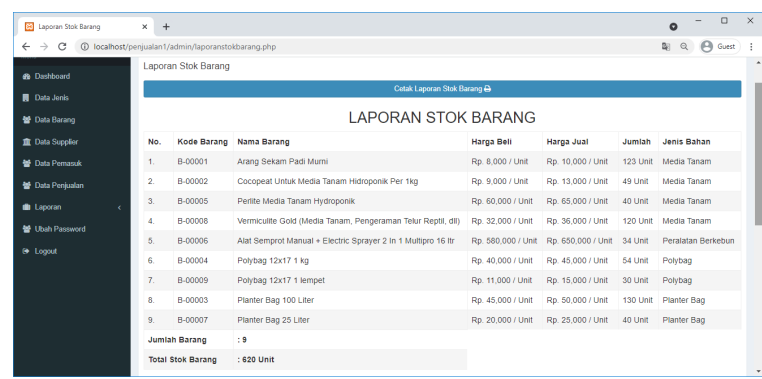

Gambar 15. Laporan Persediaan Barang

\section{KESIMPULAN}

Berdasarkan hasil perancangan sistem informasi penjualan dan persediaan produk peralatan pertanian dapat disimpulkan bahwa sistem informasi ini dapat mempermudah pekerjaan bagian penjualan perusahaan Growmart dalam pencatatan data penjualan dan pembuatan laporan dengan cepat dan efisien. Selain itu, pengolahan data barang masuk maupun persediaan barang dapat dilakukan dengan mudah dengan hasil yang akurat.

\section{REFERENSI}

[1] V. M. M. Siregar, E. Damanik, M. R. Tampubolon, E. I. Malau, E. P. S. Parapat, and D. S. Hutagalung, "Sistem Informasi Administrasi Pinjaman (Kredit) Pada Credo Union Modifikasi (CUM) Berbasis Web," J. Tekinkom, vol. 3, no. 2, pp. 6269, 2020.

[2] H. Sugara, E. Sirait, M. A. Hanafiah, and N. F. Siagian, "Sistem Informasi Pembayaran SPP Pada SMK Pembangunan Bagan Batu Menggunakan Vb.Net," J. Tek. Inf. dan Komput., vol. 3, no. 1, p. 14, 2020.

[3] S. S. S, A. T. Purba, and V. M. M. Siregar, "Sistem Pendukung Keputusan Kelayakan Pemberian Pinjaman Kredit Menggunakan Metode Topsis Pada Cum Caritas HHKBP Bagan Batu," J. Tek. Inf. dan Komput., vol. 3, no. 1, p. 1, Sep. 2020.

[4] A. T. Purba and V. M. M. Siregar, "Sistem Penyeleksi Mahasiswa Baru Berbasis Web Menggunakan Metode Weighted Product," TEKINKOM, vol. 3, no. 1, pp. $1-8,2020$.

[5] S. P. Tamba, M. D. Batubara, W. Purba, M. Sihombing, V. M. Mulia Siregar, and
J. Banjarnahor, "Book data grouping in libraries using the k-means clustering method," J. Phys. Conf. Ser., vol. 1230, no. 1, p. 012074, Jul. 2019.

[6] V. M. M. Siregar, H. Sugara, and G. A. Purba, "Aplikasi Pencatatan Laporan Penjualan Kita-Kita.Net Berbasis Web," TEKINKOM, vol. 2, no. 1, pp. 80-86, 2019.

[7] V. M. M. Siregar, H. Sugara, and I. M. Siregar, "Perancangan Sistem Informasi Pendataan Barang Pada PT. Serdang Hulu," J. Comput. Bisnis, vol. 12, no. 2, pp. 111-117, 2018.

[8] V. M. Siregar and H. Sugara, "Perancangan Dan Implementasi Aplikasi Penggajian Berbasis Dekstop Pada Murni Sadar English Course," J. Tek. Inf. dan Komput., vol. 1, no. 2, pp. 42-48, 2018.

[9] J. Simatupang and S. Sianturi, "PERANCANGAN SISTEM INFORMASI PEMESANAN TIKET BUS PADA PO. HANDOYO BERBASIS ONLINE," J. Intra Tech, vol. 3, no. 2, pp. 11-25, 2019.

[10] Fricles Ariwisanto Sianturi, "Analisa metode teorema bayes dalam mendiagnosa keguguran pada ibu hamil berdasarkan jenis makanan," Tek. Inf. dan Komput., vol. 2, no. 1, pp. 87-92, 2019.

[11] A. Ardian, I. Purnama, and V. Sihombing, "Perancangan Aplikasi Pengolah Data Siswa Berbasis Android (Studi Kasus: Mis Nurul Huda Labuhan Batu Selatan)," Pengabdi. Masy. Ika Bina En Pabolo, vol. 1, no. 1, pp. 40-53, 2019.

[12] G. J. Yanris, "Analisis Dan Implementasi Data Mining Dalam Menganalisa Kendala Akademik Yang Sering Dikeluhkan Mahasiswa AMIK Labuhanbatu (Studi Kasus : Amik Labuhanbatu)," Informatika, vol. 4, no. 1, pp. 15-24, 2016.

[13] V. Sihombing, "Aplikasi Simade (Sistem Informasi Manajemen Desa) Dalam Meningkatkan Pelayanan Administrasi di Kepenghuluan Bakti Makmur Kecamatan Bagan Sinembah Kab. Rokan Hilir Riau," SISTEMASI, vol. 7, no. September, pp. 292-297, 2018.

[14] W. Purba, S. Tamba, and J. Saragih, "The 
effect of mining data k-means clustering toward students profile model drop out potential," J. Phys. Conf. Ser., vol. 1007, no. 1, p. 12049, 2018.

[15] V. Sihombing, "Sistem Informasi Penjualan Mobil Suzuki Di Dealer Bagan Batu," SISTEMASI, vol. 7, no. 2, pp. 113119, 2018.

[16] W. Purba, S. Aisyah, and S. P. Tamba, "Perancangan Sistem Pakar Diagnosa Penyakit Mata Katarak Menggunakan Konsep Metode Runut Mundur," JUSIKOM PRIMA (Junal Sist. Inf. Ilmu Komput. Prima), vol. 1, no. 1, 2017.

[17] P. D. P. Adi and A. Kitagawa, "Performance evaluation of E32 long range radio frequency $915 \mathrm{MHz}$ based on internet of things and micro sensors data," Int. J. Adv. Comput. Sci. Appl., vol. 10, no. 11, pp. 38-49, 2019.

[18] P. D. P. Adi and A. Kitagawa, "A Study of LoRa Performance in Monitoring of Patient's SPO2 and Heart Rate based IoT," Int. J. Adv. Comput. Sci. Appl., vol. 11, no. 2, 2020.

[19] P. Dani Prasetyo Adi and A. Kitagawa, "A performance of radio frequency and signal strength of LoRa with BME280 sensor," TELKOMNIKA (Telecommunication Comput. Electron. Control., vol. 18, no. 2, p. 649, Apr. 2020.

[20] P. D. P. Adi and A. Kitagawa, "Quality of Service and power consumption optimization on the IEEE 802.15.4 pulse sensor node based on Internet of Things," Int. J. Adv. Comput. Sci. Appl., 2019. 